\section{ECOS ANTIGUOS EN VOCES NUEVAS. POS-MEMORIAS POÉTICAS DE MUJERES EN CHILE Y ARGENTINA}

\author{
ALICIA SALOMONE \\ Universidad de Chile \\ aliciasalomone@yahoo.com
}

Alicia Salomone

Doctora en Literatura, académica del Departamento de Literatura de la Universidad de Chile. Áreas de especialización: literatura y teoría crítica latinoamericana, y estudios de género. Publicaciones principales: Caminos y desvios. Lecturas críticas sobre género y poder en Hispanoamérica (Santiago de Chile, 2010, coeditado con Lorena Amaro y Ángela Pérez), Alfonsina Storni. Mujeres, modernidad y literatura (Buenos Aires, 2006), Modernidad en otro tono. Escritura de mujeres latinoamericanas 19201950 (Santiago de Chile, 2004, en colaboración con Gilda Luongo, Natalia Cisterna, Darcie Doll y Graciela Queirolo), Postcolonialidad y nación (Santiago de Chile, 2003, en colaboración con Claudia Zapata y Grínor Rojo).

\title{
RESUMEN
}

Este trabajo tiene por objetivo hacer una lectura interpretativa de una serie de textos poéticos producidos por mujeres en Argentina y Chile durante las décadas de 1990 y 2000, desde la perspectiva de la configuración poética de post-memorias y de su articulación con la experiencia de género sexual. En cuanto a la noción de post-memoria, recurrimos a las resignificaciones que, a partir de la experiencia post-dictatorial del Cono Sur, realiza la crítica chilena Gilda Waldman de las teorizaciones propuestas por Marianne Hirsch. Las que permiten dar cuenta de cómo las generaciones de hijos/as de los/las militantes de los años sesenta y setenta en América Latina elaboran sus respectivas memorias en un contexto post-traumático. En lo que hace al trabajo con la escritura misma, lo que se busca es observar cuáles son las estrategias discursivas e ideológicas que operan en la configuración poética de dichas post-memorias.

Palabras clave: poetas chilenas y argentinas, post-memoria, experiencia post-dictatorial.

\section{ABSTRACT}

This work aims to analyze a series of texts by Chilean and Argentine recent poets (19902000), focusing on the poetic articulation of post-memories as well as gender experiences. The notion of post-memory is developed by Chilean literary critic Gilda Waldman, who re-reads ideas by Marianne Hirsch, in order to observe how the generations of sons and daughters of Latino American militants of the sixties and seventies elaborate their own memories in a posttraumatic context. In terms of the writing itself, the objective of this text points to observe both discursive and ideological strategies that make possible the poetic configuration of these post-memories.

Key words: Chilean and argentinean poets, post-memory, post-dictatorial experience.

\section{Post-memoria y poesía de mujeres}

La crítica chilena Gilda Waldman (2007, pp. 387-401), resignificando conceptualizaciones propuestas por Marianne Hirsch para la experiencia del Holocausto, sugiere que adoptemos la idea de post-memoria como un modo de entender las complejidades que, en el contexto post-dictatorial del Cono Sur, presentan las memorias de individuos nacidos durante o con posterioridad a las dictaduras ${ }^{2}$. En muchos casos, se trata de personas que no protagonizaron hechos traumáticos, y que incluso pueden no tener recuerdos directos sobre los mismos, pero que fueron afectadas en su condición de familiares o conocidos de
1

Este artículo se enmarca en el desarrollo de dos proyectos de investigación, de los cuales soy Investigadora Responsable: Proyecto Fondecyt 1110083 y Proyecto DI (VRID-U. Chile) 10-02/2. Mucho agradezco los comentarios de mis colegas Gilda Luongo, Milena Gallardo y Grínor Rojo.

Prefiero la denominación postdictadura a la de transición democrática para definir el período posterior a la salida de los militares de los gobiernos en el Cono Sur, pues la primera denominación no anula la dimensión conflictiva que tienen dichos procesos tanto en el plano político-social como cultural y simbólico.
Ecos antiguos en voces nuevas. Pos-memorias poéticas de mujeres en Chile y Argentina

ALICIA SALOMONE 


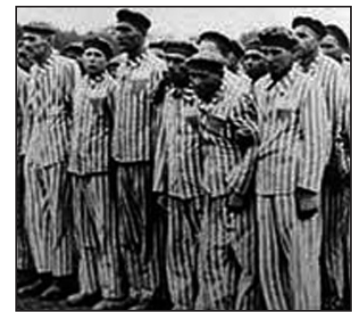

Holocausto nazi.

3

En concordancia con el enfoque propuesto acerca de las postmemorias, en esta ocasión consideraré un corpus pequeño de textos, el que se irá ampliando a lo largo de esta investigación en curso.

4

Elizabeth Jelin (2001), adopta la noción de «trabajos de la memoria» para referirse a los procesos de rememoración en los que los sujetos asumen un rol activo y creativo frente a ciertas experiencias límite, generando nuevos sentidos sobre el pasado desde una toma de distancia crítica respecto de lo vivido. Esta perspectiva se diferencia de formas traumatizadas de experimentar la memoria, en las que el pasado invade el presente bajo la forma de una fijación en un retorno compulsivo al lugar de trauma sin permitir la conclusión del duelo ni a la elaboración del dolor.

5

Me refiero al debate que inicia Theodor W. Adorno con su afirmación acerca de que no sería posible escribir poesía después de Auschwitz, y que es contestado, desde distintas perspectivas, por autores tales como Giorgio Agamben y Alain Badiou.

6

Aludo aquí al concepto elaborado por la lingüista Patrizia Violi (1991), quien define la experiencia de género-sexual como el modo en que los y las sujetos dan cuenta en sus discursos de las vivencias que tienen en tanto seres sexuados.

Ecos antiguos en voces nuevas. Pos-memorias poéticas de mujeres en Chile y Argentina

ALICIA SALOMONE víctimas directas. Como sostiene Waldman a partir de Hirsch, estas personas con frecuencia crecieron dominadas por relatos sobre hechos que precedieron a sus nacimientos, $\mathrm{y}$ que tienden a desplazar a los propios impactando sus subjetividades con discursos relativos a situaciones que no pueden comprender ni recrear cabalmente. Así, en el proceso de reelaborar sus memorias, estos sujetos suelen presentar desconexiones o lagunas en sus discursos y, por lo tanto, deben apelar a un esfuerzo imaginativo a fin de completar los nexos entre acontecimientos y referentes que no pueden derivar de su propia experiencia. La post-memoria, concluye Waldman, surge en una situación de pérdida de continuidad, ante una fractura histórica y social, y encuentra su origen en una memoria ausente, que es reemplazada por silencios o relatos fragmentarios, configurándose como memorias de segunda o tercera generación que son modeladas con retraso por la historia de las generaciones precedentes (Waldman, 2007, p. 395).

En relación con estas consideraciones, me propongo reflexionar acerca de la configuración de post-memorias, abordándolas desde la revisión de la poesía contemporánea de mujeres de Argentina y Chile. Desde mi perspectiva, y esa es la hipótesis que guía este trabajo, en estos textos es posible encontrar huellas de los modos en que la generación de los hijos e hijas de los militantes de los años sesenta y setenta redefinen sus subjetividades en un contexto post-traumático. Ello supone, por una parte, la necesidad de visibilizar discursos ideológicos que remiten a trabajos con la memoria y con el duelo que difieren sensiblemente de los que llevó a cabo la generación de sus padres ${ }^{4}$ y, por otra parte, observar cómo dichas experiencias se trasponen a la escritura mediante lenguajes y recursos expresivos (poéticas, estilos, imágenes y procedimientos discursivos) que también son específicos. Esto es lo que observaré a través del análisis de ciertos textos producidos por tres poetas de Chile y Argentina, cuyas infancias transcurren durante las dictaduras que afectaron a sus respectivos países durante las décadas de 1970 y 1980. Ellas son Roberta Iannamico (Bahía Blanca, AR, 1972), Verónica Viola Fisher (Buenos Aires, 1974) y Alejandra del Río (Santiago de Chile, 1972).

Quisiera agregar una justificación adicional respecto de mi opción por trabajar con la poesía, y con la poesía de mujeres en parti- cular. Con respecto a lo primero, la elección tiene que ver con el hecho de que si bien este género literario, desde hace varias décadas, es asumido como un espacio textual particularmente idóneo para rastrear la plasmación discursivo/literaria de experiencias traumáticas, no ha sido priorizado a la hora de revisar las memorias de nuestro pasado reciente ${ }^{5}$. A la deslegitimación del género en relación con el tema, en el caso de la poesía de mujeres, es preciso agregar una dimensión que reproduce y duplica a la anterior. Se trata de una exclusión de género-sexual que tiende a generar una invisibilización o minusvaloración, en los textos poéticos de mujeres, no sólo de sus múltiples búsquedas expresivas, sino de los discursos relativos a lo político e ideológico $y$, más ampliamente, de todo el tejido intertextual que ellos traman con el contexto de producción del cual emergen.

Esta exclusión relativa, sin embargo, es particularmente estimulante a los fines de este estudio. Pues, dado su posicionamiento marginal dentro de una sociedad como la latinoamericana, donde todavía impera una fuerte diferenciación jerárquica entre lo considerado masculino y femenino, en este corpus poético es frecuente encontrar lecturas alternativas, basadas en una reflexión crítica sobre la experiencia de género-sexual femenina ${ }^{6}$. Visiones que se articulan desde un cuestionamiento a los binarismos ideológicos que vertebran la cosmovisión falogocéntrica (masculino/femenino, actividad/pasividad, público/privado, razón/emoción, etc.), y que deconstruyen no sólo a la feminidad hegemónica sino también los relatos dominantes sobre la nación y su historia.

\section{Imagen poética y recuperación de la me- moria}

Andrés Avellaneda (2003, p.119), en un análisis de las estrategias ideológicas y ficcionales de la literatura argentina de finales del siglo $\mathrm{XX}$, sostiene que la relación entre escritura y política interesa más por las elecciones discursivas y retóricas plasmadas en los textos que por su capacidad para enunciar contenidos referidos a temas o proyectos ideológicos particulares. Afirma el autor que los textos más innovadores cuestionan, primero que nada, los usos de la lengua, aunque por esa vía también puedan conmover los saberes establecidos, incluso los políticos o ideoló- 
gicos. En una postura cercana a la anterior, Miguel Dalmaroni (1993, pp. 9 y ss.) también se refiere al vínculo entre literatura y política desde la poesía de Juan Gelman, advirtiendo que, aun en las escrituras donde esa conexión pudiera parecer evidente, lo importante es detectar cómo lo político se traduce en términos poéticos o en un estilo. Pues, incluso en esos textos donde poesía y política parecieran fundirse, la ideología se trasvasija, fundamentalmente, desde ciertas figuras de lenguaje, evidenciando el poder de significar que arrastran las palabras.

Me interesa sobremanera, para los propósitos de este trabajo, la contribución de Alicia Genovese (2010, pp. 69-76), quien, al interrogarse sobre la inscripción literaria de las memorias recientes, destaca el potencial que tiene la imagen poética para evocar sensaciones y percepciones, superando con mucho las posibilidades que ofrecen los llamados géneros referenciales, tales como los testimonios, los diarios íntimos o las cartas. Si bien para Genovese estos géneros fueron cruciales a la hora de instalar las demandas de justicia en el Cono Sur, articulando la palabra de las víctimas como las reflexiones surgidas desde las ciencias sociales, considera que los géneros testimoniales presentan límites o aporías cuando se trata de poner en palabras ciertas experiencias traumáticas. Límites que se manifiestan en la presencia de vacíos en el discurso, que dejan traslucir que hay algo que no puede ser dicho, que está más allá del discurso verbal y que, por ende, necesita ser recuperado desde otro lugar.

El género poético, en cambio, al eludir la literalidad o referencialidad directa, en tanto la imagen poética se manifiesta de modo indirecto o sesgado, permitiría relacionar las percepciones inmediatas con otras estratificaciones de sentido. De este modo, si la imagen poética, por un lado, permite eludir el rechazo que puede provocar la literalidad del testimonio, por otro, multiplica las posibilidades interpretativas de los signos. Así, desde esa condición autorreflexiva que es propia del género, en el sentido de reflexio o cambio de dirección, la imagen poética siempre queda abierta, posibilitando desplazar la mirada hacia otras direcciones y estimular transformaciones a nivel de la subjetividad. Como si mirar de costado la muerte o la sordidez de la prisión, concluye Genovese, hiciera posible, al mismo tiempo, conectarse con el enorme reservorio vital que subyace en la existencia humana y que, sin embargo, es pocas veces percibido (Genovese, 2010, p. 70).

Por mi parte, siguiendo la sugerencia de Genovese asumo aquí el ejercicio poético como una praxis estética que excede, sin embargo, a esta sola consideración, para proyectarse también como un espacio idóneo para promover una resilencia en los y las sujetos que la producen y recepcionan. Ello, desde el entendido que la noción de resilencia nombra esa capacidad humana que nos permite sobrevivir a las más difíciles circunstancias de la vida e incluso salir fortalecidos y transformados por ellas?

\section{Post-memorias poéticas en la generación de HIJOS ${ }^{8}$}

Como anticipé en un comienzo, me interesa trabajar especialmente con tres de las poetas que advienen al escenario poético de Argentina y Chile entre finales del siglo XX y los inicios del presente. En el marco de la reflexión que he planteado, sus textos me permiten comprender cómo las generaciones más jóvenes se hacen cargo, literaria e ideológicamente, de la pesada herencia recibida desde la generación de sus padres. Herencia que remite a una historia trágica, como es la derrota inflingida a los proyectos de transformación radical que se impulsaron hace tres o cuatro décadas en América Latina, y que a su vez se prolonga en la devastadora represión desatada por las dictaduras.

Alicia Genovese (2003, pp. 199-214), en un estudio sobre la poesía joven producida en la Argentina en los años noventa, descubre que estos textos con frecuencia aluden a la violencia política de los años de la dictadura. Esos reenvíos, por otra parte, suelen plantearse desde una mirada muy poco complaciente, y hasta impiadosa, no sólo respecto de los hechos que tuvieron lugar en el espacio público, sino también sobre las actuaciones del ámbito íntimo/privado. Con relación a esta última dimensión, lo que observamos es que en esta poesía el hogar familiar no suele aparecer como un lugar de cobijo y resguardo donde hijos e hijas pueden crecer seguros. Por el contrario, la casa y los vínculos próximos se vuelven territorios precarios y potencialmente peligrosos, cuando no son la caja de resonancia desde la cual esa generación experimentó el horror que se desataba en el afuera.

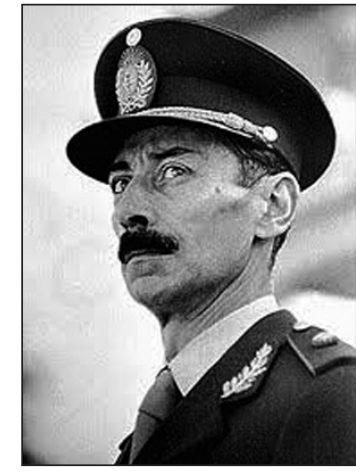

Videla.

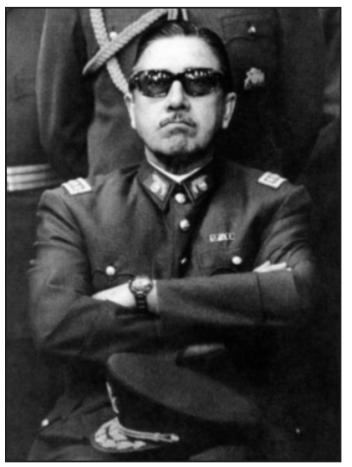

Pinochet.

7

Cf. Helena Combariza, «La resilencia. El oculto potencial del ser humano", en http://aiur. us.es/ kobukan/la resilencia. $\mathrm{htm}$. Consulta del 1 de marzo de 2009 .

8

Aludo aquí a la denominación que adopta la organización «Hijos e Hijas por la Identidad y la Justicia contra el Olvido y el Silencio (H.I.J.O.S.)», creada en la Argentina en 1995. Esta entidad agrupa a hijos de desaparecidos, asesinados, presos políticos y exiliados durante la dictadura militar y años anteriores, y también incluye a jóvenes que, sin haber sufrido en su familia la represión directa, asumen que fueron afectados por una historia común. Cf.: http://www.hijos-capital.org. ar/index.php?option=com con tent\&view $=$ article\&id $=20 \&$ ltem $i d=399$. Organizaciones de objetivos semejantes se han constituido recientemente en Chile (cf: http://hijoschile.blogspot. com/) y Uruguay (cf: http:// hijosuruguay. blogspot.com/). Consulta del 23 de septiembre de 2011

Ecos antiguos en voces nuevas. Pos-memorias poéticas de mujeres en Chile y Argentina

ALICIA SALOMONE 
Jorge Monteleone, «Poetas en la mitad de la vida», en http://www.lanacion.com. ar/1188416-poetas-en-lamitad-de-la-vida (consulta del 27.2.2011).

10

A partir del procesamiento $y$ condena de las tres primeras cúpulas militares, después de la recuperación de la democracia en la Argentina, en diciembre de 1983, durante los años 90 se impusieron distintas políticas que concluyeron con el indulto a los militares que habían sido condenados por crímenes de lesa humanidad. En los 2000, sin embargo, comenzó la reapertura de los juicios, lo que devolvió a prisión a varios de ellos.
Ecos antiguos en voces nuevas. Pos-memorias poéticas de mujeres en Chile y Argentina

ALICIA SALOMONE
Teniendo en cuenta estas representaciones, es comprensible la centralidad que en el discurso de las nuevas generaciones poéticas cobra el intento por rearmar la memoria de esos años formativos. Jorge Monteleone detecta una urgencia de estos sujetos por instaurar un relato, pero sin contar para ello con una épica ni con una tradición válida que les llegue de sus ancestros9. De allí que, en estas recuperaciones memoriosas, más que idealizaciones del pasado, lo que descubre es la manifestación de una micropolítica donde las figuras parentales tienden a proyectar el universo opresivo de la dictadura. Por mi parte, advierto que esas búsquedas por rearmar la propia historia suelen traducirse, en Argentina y también en Chile, en un recurrente retorno del sujeto al hogar primero, al que vuelve, una y otra vez, como si allí radicara la clave de un relato que ha quedado trunco. Es pues habitual que quien enuncia esta poesía sea un/a joven que se encuentra frente a un vacío de memoria, a una suerte de duelo sin objeto, que se traduce tanto en una nostalgia profunda respecto de algo que no alcanzó a vivir y tampoco sabe nombrar, como en sentimientos de rabia y dolor frente a situaciones de violencia o pérdida experimentadas dramáticamente en el espacio íntimo.

Revisando la narrativa argentina de los 90 , Andrés Avellaneda (2003, p. 131) advierte que la representación de la memoria fue un núcleo semántico de resistencia desde el cual se confrontó el discurso oficial de reconciliación y olvido frente a los crímenes de la dictadura ${ }^{10}$, y si bien esta situación varió durante los 2000 (el artículo de Avellaneda es de 2003), su opinión es enteramente válida para la década del noventa. Al respecto, dice el autor que el rasgo distintivo de esas escrituras fue la incomodidad para practicarlas, lo que se manifiesta en la utilización de estrategias alusivas y alegóricas que permiten desterritorializar o desplazar en el tiempo los asuntos contemporáneos que se quiere problematizar. Estos mecanismos, por otra parte, también están asociados a nuevas expectativas escriturales, las que ya no buscan decir lo indecible o lo prohibido sino articular aquello que aún no tiene nombre. En este sentido, concluye Avellaneda, en estas ficciones no se intenta revelar un sentido ausente $u$ oculto sino producir otro que se ignora o cuya existencia es incierta.

Es interesante observar cómo esas experiencias y estrategias escriturales también se hacen presentes en la producción poética, dando cuenta de los múltiples tráficos que se producen entre escritura y memoria. En este sentido, Alicia Genovese observa que en las memorias poéticas de los noventa se manifiestan diversas modalidades expresivas, en especial la hibridación entre el discurso poético y otros tipos de discurso, como los de la publicidad o los mass media. Lo que, en opinión de Genovese (2010, p. 202), torna borrosa la distinción entre lo culto y lo popular, lo alto y lo bajo, y termina por cuestionar la condición cerrada o pura de la poesía. Advierte la autora, sin embargo, que este procedimiento es ajeno a toda ilusión de transparencia o de facilidad, pues, aun incluyendo materiales disímiles en su construcción, la poesía continúa situándose en tensión o ruptura frente a la eficiencia y locuacidad de lo massmediático, lo que le permite interferir esos discursos con «el fantasma del exilio o de la marginalidad» (Genovese, 2010, p. 212).

En el escenario chileno, el crítico Javier Bello (2011, pp. 41-43) da cuenta igualmente de cómo la poesía joven de los años noventa se hace cargo de un reflote de la memoria traumática que se materializa en una cerrazón de la poesía. Una escritura que no construye macro-relatos ni historias fuertes sino que se modela en base a fragmentos de historias, de sujetos, de cuerpos, de emblemas y paisajes, tomando forma en imágenes escatológicas pobladas de restos, escombros, ruinas, rehechos, fantasmas, eriazos y demoliciones, que son el escenario donde instalar una palabra en fuga que permite exhibir el vacío de las formas ausentes y la mudez de las palabras inefables.

\section{Niñas lúcidas/mujeres críticas en las post- memorias poéticas de mujeres}

Voy ahora a los textos de dos poetas de Argentina y una de Chile, publicados entre 1995 y 2009 , que son significativos en relación con las problemáticas que vengo desarrollando. Ponen estos textos en escena una serie de imágenes que, evidenciando la densidad personal y política que posee la experiencia de la infancia, así como la productividad estética que ofrecen las dinámicas de la imaginación infantil, permiten dilucidar las vías a través de las cuales transita la configuración de las postmemorias que las distintas sujetos ponen en juego. Entre las figuras que quiero comentar, la primera corresponde a la de una mujer que 
se interroga sobre la relación entre pasado y presente, incluyendo la trayectoria de la genealogía femenina que la ha constituido como tal; la segunda habla de las vivencias y estrategias de una hablante que en la infancia se ve expuesta a la violencia extrema, casi hasta el punto de provocar en ella una disolución identitaria; y la tercera remite a la relación que establece otra hablante en su relación temprana con la muerte y con la escritura. Representaciones que tienen en común el ofrecer una visión descarnada sobre lo vivido, que se articula, al mismo tiempo, con una perspectiva autorreflexiva que elude la desesperanza, abriendo la posibilidad de una transformación de las propias subjetividades.

- La niña/mujer y su herencia genealógica: Roberta Iannamico

En el escenario poético argentino de los últimos años, destaca la obra de Roberta Iannamico, poeta nacida en la ciudad patagónica de Bahía Blanca en 1972, quien proyecta su escritura desde un registro íntimo y doméstico hacia un microcosmos plagado de objetos cotidianos, y donde son recurrentes las escenas y juegos de la infancia. En estos cuadros, los elementos ficcionales, potenciados por la apelación a la imaginación infantil, se conjugan con ciertas experiencias autobiográficas que, a primera vista, pueden parecer descontextualizadas o banales. Esto es lo que ocurre con la emergencia de ciertas imágenes antiguas, de una televisión en blanco y negro, que cobran un sentido diferente cuando las pensamos como fragmentos de una historia fracturada que ya no puede ser reconstruida como un gran relato, pero que se rearma desde una discursividad íntima que aparece inevitablemente interferida por referentes que provienen del contexto social.

En el poema «Caracoles», incluido en la antología Niña bonita ${ }^{11}$, publicada en 2000, la hablante recuerda las figuras de unas cebras aparecidas en un viejo programa de TV, sobre las que ella despliega una serie de alusiones irónicas basadas en la superposición de rayas: las de los cuerpos de los animales, las del traje asociado a los presos y las de los barrotes de las rejas proyectados sobre un cuerpo blanco. Desde estas imágenes simbólicamente recargadas, la hablante desliza un sarcasmo sobre una realidad donde las diferencias son aparentemente claras (blanco o negro), pero que ella

intuye degradada e incomprensible. Un mundo donde los tiempos parecen confundirse pues, tanto en el ayer como en presente de la enunciación del poema, que prolonga la impunidad de los crímenes cometidos hace más de treinta años, los malvados imponen su ley y conviven siniestramente con los inocentes:

todos sabemos
que una cebra tras las rejas
es una redundancia
así que hacen lo que se les canta
...
Hacen el mal sin mirar a cuál
atacan con fiereza
después brindan ${ }^{12}$.

En dos poemas de El collar de fideos (2001), que siguen el hilo de un mismo relato, la voz poética cambia de enfoque $y$, volviendo la mirada sobre sí misma, hace una revisión de la genealogía femenina que recibe como herencia familiar. Transitando desde lo individual a lo colectivo, la hablante ausculta memoriosamente sus vínculos primarios, en particular la relación con su madre, interrogándose sobre el eje genealógico que concluye en la sujeto que ha llegado a ser. Desde un posicionamiento que parece haber hecho propias las visiones de las poetas feministas que la antecedieron, y echando mano de la ironía que es característica en muchas de ellas, la hablante relaciona su vivencia inmediata con los condicionamientos que históricamente encarnan en los cuerpos de mujeres («todas nos empezamos a parecer a nuestras mamás...»). Un ejercicio a través del cual devela esos actos y afectos que, arraigados en esos cuerpos, modelan las subjetividades desde la interiorización de una violencia simbólica, cotidiana y naturalizada, que lleva el sino de la auto-destrucción («mi bisabuela se suicidó / cuando mi abuela tenía / siete años»):

Todas nos empezamos a parecer a nuestras mamás cuando pasa el tiempo

nos ponemos grandotas

percheronas

la mirada

más hermosa

como de alguien que puede

defenderse de todo

como de alguien que está enamorada de sí misma

en los momentos de soledad (Iannamico, 2001, p. 17).

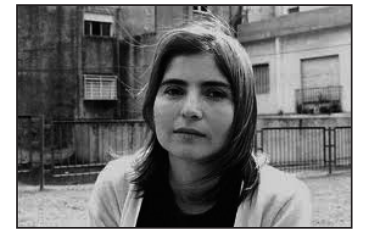

Roberta lannamico.

11

Refiriéndose a los poemas de la antología La niña bonita, publicada por Alción (Córdoba, 2000), donde se recogen textos de poetas nacidos/as entre 1968 y 1976, Jorge Monteleone observa la presencia del pasado como conflicto, búsqueda, apelación y nostalgia. Aclara, sin embargo, que no se trata del pasado trascendente de un linaje, de una historicidad, o de un legado, sino otro, más cercano, donde el presente se refugia en un momento cualquiera. $Y$ a ello agrega otra referencia tomada de los poemas: la sospecha inquietante de que hay algo perdido, acaso grandioso, terrible o intenso, que ya no está - quizás nunca estuvo, "pero cuyas equívocas señales parecen vivir en el lenguaje o en la costumbre». Cf. Jorge Monteleone, Reseña bibliográfica «La niña bonita: entre el presente y la memoria», en http://proyectovox. org.ar/virtual $3 . h$ htm (consulta del 27.3.2011).

12

Dado que no he podido acceder al texto original, cito el poema a partir de la referencia de Genovese (2010, p. 205).
Ecos antiguos en voces nuevas. Pos-memorias poéticas de mujeres en Chile y Argentina ALICIA SALOMONE 


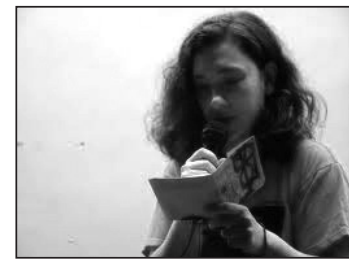

Verónica Viola Fisher.

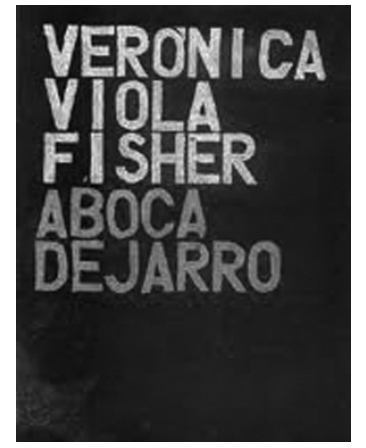

13

En Deshacer el género (2006), Judith Butler afirma que cada sujeto se convierte en viable a partir de la experiencia del reconocimiento, pero los términos en que éste se otorga dependen de cada contexto $y$, por ende, son variables. En este sentido, los mismos términos que otorgan la cualidad de "humano» a ciertos individuos pueden privar a otros de la posibilidad de lograr dicho estatus, generando un diferencial entre lo que se considera humano y menos humano (abyecto). Vinculando su reflexión con la problemática de génerosexual, se pregunta la autora: «Si soy de cierto género, ¿̇seré todavía considerado como parte de lo humano? ¿̇Se expandirá 'lo humano' para incluirme a mí en su ámbito? Si deseo de cierta manera, ¿seré capaz de vivir? ¿Habrá un lugar para mi vida y será reconocible para los demás, de los cuales dependo para mi existencia?» (p. 15)

Ecos antiguos en voces nuevas. Pos-memorias poéticas de mujeres en Chile y Argentina

ALICIA SALOMONE
Todas las madres

guardan la memoria de la primera

mi bisabuela se suicidó

cuando mi abuela tenía

siete años

-una traición de amor-

tomó el veneno y estrelló

la jarra contra la pared

delante de su hija

dicen que primero

se preparó

se pintó

se puso las alhajas

se peinó el pelo rubio

frente al espejo

sin dejar de mirarse

con ese gesto que repite

todos los días mi mamá

y que yo

estoy empezando

a repetir (Iannamico, 2001, p. 26).

- La niña y la violencia extrema: Verónica Viola Fisher.

Verónica Viola Fisher, nacida en Buenos Aires en 1974, es la segunda poeta argentina que aquí me interesa. En su trabajo el nexo entre memoria política y género-sexual también aparece claramente referido, como queda en evidencia en su poemario de 1995: Hacer sapito. Este texto, articulado desde una enunciación dura y sarcástica, que también echa mano de un registro autobiográfico, expone de manera cruda la forma como la subjetividad de la hablante queda determinada por la voz y la mirada de un padre feroz, quien no sólo no experimenta el amor filial, sino que incluso carece de los atributos mínimos de compasión que debieran caracterizar a la condición humana. Esta figura, que emerge en el poema como el dueño absoluto del poder y el portador de toda verdad y conocimiento, un rasgo que se remarca en la fuerza implacable de una mirada que puede decidir la (in)existencia de su hija, es el referente respecto del cual la hablante no puede sino configurarse como un sujeto anómalo, abyecto, en tanto la exposición de su diferencia femenina ineludiblemente evidencia el fracaso de las expectativas paternas, asentadas de modo brutal en el patriarcalismo y la heteronormatividad ${ }^{13}$. Así, dice la hablante, parodiando la voz del padre:
Yo sé

sobre todo

punto de vista

sos ciega

porque yo

no te veo (Viola Fisher, 2005, p. 43).

Revisando su propia historia desde el momento de la concepción hasta su presente adulto, la hablante logra distanciarse, sin embargo, de esa figura siniestra y ubicarse en relación a ella desde una distancia crítica. Lo que, por un lado, le permite poner a resguardo la propia subjetividad, diferenciándose como un sujeto distinto frente a ese ser omnipotente que la informa desde dentro. $\mathrm{Y}$, por otro, la habilita para emitir una voz denunciante respecto de las formas en que la opresión familiar y la represión socio-política operan estrechamente relacionadas. Esto último es lo que surge en uno de los poemas del libro, donde con una sintaxis quebrada, que vehiculiza una enunciación angustiosa y entrecortada por efecto del dolor, y apelando a una alternancia entre tiempos verbales pasados y presentes que instala un nexo entre esos cronotopos aparentemente separados, la hablante va reviviendo una escena de infancia en la que experimenta el maltrato paterno a grado sumo. Ello, al punto que el sentimiento que le produce el recuerdo de una ejecución musical, a la que se ve forzada por el padre, se transmuta en la vivencia de una sesión de tortura, ejercida por él mismo sobre el cuerpo de su hija, la que es aplicada desde una lógica cosificadora y destructiva del otro(a) que es homóloga a la que imponía el régimen militar sobre sus contradictores.

Hay una pieza
honda
creación del sordo
no me oyó
entrar
cargando mis nueve
años de pupila
por deber
son nueve
mil voltios
a mis manitos si no toco
para mi padre
para Elisa no
era Beethoven
el sordo
en la pieza




\author{
una sombra fue \\ mi padre y su hija \\ frente al piano \\ preparó \\ la partitura y la \\ picana \\ para Elisa no \\ para su hija no para de \\ tocar \\ jamás \\ el enchufe» (Viola Fisher, 2005, p. 37). \\ - La niña, la muerte, la escritura: Alejandra
} del Río

Volviendo la mirada al escenario chileno, es posible afirmar que varios de los rasgos con que caracterizamos la escena poética argentina, también aparecen en este otro espacio nacional. El que, con sus particularidades históricas, igualmente enfrenta los conflictos socio-simbólicos que supone buscar una recomposición identitaria en tiempos postdictatoriales. Así, no puede extrañar que en los textos de las nuevas generaciones resuenen los ecos de un pasado familiar que siempre aparece vinculado a una historia mayor, que es la del país y su carga de tragedia. Por otra parte, y en relación con la poesía de mujeres de los años ochenta ${ }^{14}$, también es frecuente encontrar, tanto en la escritura de mujeres como en la de varones, una visión crítica de los patrones sexo-genéricos tradicionales que fueron tan ampliamente explotados por el nacionalismo militar chileno. En este sentido, como señala Javier Bello (2010), en el período de la transición, la articulación de una mirada crítica sobre el patriarcalismo suele ser concomitante con el surgimiento de discursos acerca del cuerpo y la sexualidad que comienzan a desplazarse por fuera de las normas androcéntricas y heteronormativas.

Algunos de los textos que integran el poemario material mente diario 1998-2008 (2009), de Alejandra del Río (Santiago, 1972), pueden ser leídos desde esas coordenadas, tanto en lo que hace a la revisión de la propia infancia en clave política como a la inflexión de género-sexual que se relaciona con ella. En este contexto, vale la pena retomar el comentario de Lorena Amaro, quien destaca el trayecto de retorno que define la dinámica del libro. Pues, más allá de los extensos recorridos que despliega la hablante, desplazándose por un sinnúmero de tradiciones poéticas y ciuda- des lejanas, desde Berlín o Praga al Rangoon nerudiano y la mítica Sión, el gesto fundamental que deja asentado en el texto es el del regreso: «y regresa a sus lugares como animal herido para enunciar un poema agónico en el cuarto de la infancia», para desde allí volver a salir y retornar herida ${ }^{15}$. En efecto, como descubre Amaro, la hablante del poemario insiste en la afirmación del retorno a un país cruel y perdido, al cual, sin embargo, ella convoca amorosamente, desde la fidelidad a un espacio originario donde ha radicado el inicio de un proceso de maduración personal y de desarrollo creativo que está estrechamente ligado a la escritura.

Esta invocación es la que queda explicitada en el poema «Simultánea y remota» (Santiago de Chile, año 1980), un texto donde la hablante lleva a cabo esa vuelta simbólica, a la vez momentánea y eterna, al cronotopos de la infancia. De hecho, la escena que relata el poema es recreada desde la voz de una niña, lúcida y en absoluto inocente, que es capaz de percibir la tensión del entorno feroz que la rodea y al que percibe a punto de estallar. Es la voz de esa pequeña, entonces, la que nos interpela desde un pasado que, al igual que lo que en los textos de las poetas argentinas que revisamos antes, aparece como tremendamente próximo. Un cronotopos ambiguo desde el que nos advierte que habita una casa cercada, no por monstruos imaginarios, sino por amenazas latentes y reales, y donde este ser desamparado, que insiste obsesivamente en recordarnos que sólo tiene ocho años, no encuentra el anclaje vital que demanda su supervivencia.

Inmersa en este ambiente persecutorio y emocionalmente frágil, sólo la escritura despuntará salvadora para ella, como antes lo fue para su doble: Ana Frank, esa otra niña con quien comparte, no sólo el miedo ante la persecución, sino la vivencia de cómo la escritura puede operar como un ámbito de resguardo y reconfiguración identitaria, aun bajo las condiciones más extremas. Una escritura que, en el caso de la hablante del poema, toma forma en la emergencia de una poesía inicial, que ella no puede sino asociar con la impronta que deja en su imaginación infantil una de las preguntas nerudianas: ¿por qué se suicidan las bojas cuando se sienten amarillas?

Tengo ocho años

vivo en una ciudad sitiada por el ojo carnicero

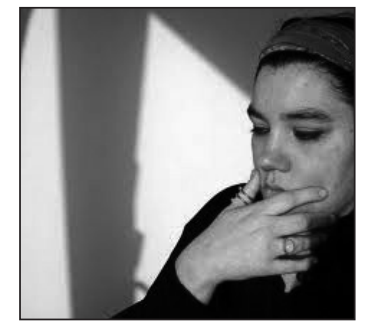

Alejandra del Río.

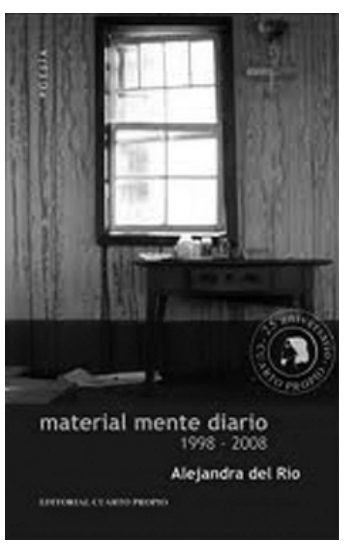

14

Me refiero aquí a ese conjunto de voces poéticas que emergen en Chile en la década del 80 y que son visiblemente influidas por el movimiento y la reflexión feminista que eclosiona en esos años, donde destacan las figuras de Elvira Hernández, Soledad Fariña, Verónica Zondek, Marina Arrate, entre muchas otras.

15

Lorena Amaro, "La enfermedad del regreso. Material mente diario de Alejandra del Río», http://lacallepassy061.blogspot.com/2009/09/la-enfermedad-del-regreso-material. html (consulta del 25 de abril de 2010).

Ecos antiguos en voces nuevas. Pos-memorias poéticas de mujeres en Chile y Argentina

ALICIA SALOMONE 
La "estructura de sentimiento», según Williams (1980), es una categoría que nos permite observar cómo los significados y valores son vividos $y$ sentidos activamente por los sujetos, y a su vez cómo esos sentimientos y creencias se relacionan con las ideas sistemáticas y formalmente sostenidas. No se trata de una oposición entre pensamiento y sentimiento, sino de cómo el pensamiento es sentido y de cómo el sentimiento es pensado, lo que supone una conciencia práctica de tipo activa, inmersa en una continuidad viva e interrelacionada.

Ecos antiguos en voces nuevas. Pos-memorias poéticas de mujeres en Chile y Argentina

ALICIA SALOMONE mi vida transcurre tras los armarios de Ana Frank

y cuando salgo a la escuela

noto miradas esquivas

[...]

Tengo ocho años

mis ocho años no tienen inocencia

en casa pregunto

Nada se me oculta

[...]

Tengo ocho años y un cisne

durmiendo el sueño mortal en mi hombro

insisto en hacerme una pregunta

¿por qué se suicidan las hojas

cuando se sienten amarillas? (del Río, 2009, pp. 64$65)^{16}$.

Las distintas escrituras que hemos venido revisando hasta aquí pueden ser leídas como la plasmación poética de heridas y resistencias que, con tesón, regresan a la página para volver a ser nombradas. Esta poesía, sin embargo, también puede ser vista como un territorio textual donde es posible detectar una sostenida capacidad de resiliencia, a la que entendemos como la búsqueda de una supervivencia personal y colectiva que merezca la pena ser vivida. Otro poema de Alejandra del Río, también de material mente diario, traduce cabalmente esta visión, enfatizada en la elección de un título («Resiliencia») que precisamente incorpora ese concepto para aludir a una explícita voluntad de sobrevida.

Nunca jugábamos a ser madres

sólo en historias de terror

Abandonaban niños en la puerta de la casa
vivos y muertos
debíamos enterrarlos
formar un sindicato de huérfanos
implantar su reino de justicia
[...]
La muerte era nuestra niñera de día y de noche
bebía en el salón junto a los conspiradores

La muerte se sentaba a la cabecera

vigilaba compadecida su guadaña

se quedaba quieta

alcanzaba a rozar algunos rizos

algunos miembros prescindibles (del Río, 2009, pp. 62-63).

En el caso de este texto, esa posibilidad de sobrevida es recreada desde la voz de una hablante, ya no niña sino adulta, que ha logrado sobreponerse al riesgo extremo que ha experimentado en el pasado, y que puede recordar con ironía aquellos juegos infantiles con sus amiguitas del barrio, los que se desplegaban en medio de un escenario de muerte. De forma semejante a lo que comentamos a propósito de uno de los poemas de Roberta Iannamico, en los juegos que recrea Alejandra del Río también se recuperan elementos de la imaginación infantil. Por ejemplo, en el recuerdo de unas escenas donde las niñas encarnaban proyectivamente a sus madres y mayores en unas historias de terror inventadas en las que pululaban huérfanos y se enterraban niños muertos. A diferencia de lo que ocurría en la realidad social, sin embargo, en estas dramatizaciones ellas lograban implantar un cierto «reino de justicia» $y$, mediante la administración de una lógica propia, podían exorcizar los demonios que las acosaban en su contacto cotidiano con realidades que eran inasimilables. De hecho, quizás sea la propia supervivencia de la hablante-adulta, y la solidez de su enunciación poética, la prueba más fehaciente de la efectividad vital y estética de aquellas estrategias lúdico-creativas.

\section{Palabras finales}

A lo largo de este texto busqué explorar la productividad de la poesía, y particularmente de la poesía joven de mujeres de Chile y Argentina, para indagar en la elaboración de discursos de post-memoria, relacionados con las consecuencias de la imposición del terrorismo de Estado en los países del Cono Sur de América. Me interesó observar cómo dichas recuperaciones memoriosas se plasman en estrategias escriturales e ideológicas que parecen ser comunes a los hijos e hijas de la generación de los militantes de los años sesenta y setenta tanto en Argentina como en Chile. Apelando a las conceptualizaciones de Raymond Williams, podría hablarse así de una «estructura de sentimiento» que se hace presente no sólo en cada espacio nacional sino, de manera transversal, en las producciones poéticas a ambos lados de la cordillera de los Andes, dando forma a discursos y estilos que, habiendo sido forjados en contextos de producción parecidos, también establecen entre ellos semejanzas y diálogos intertextuales ${ }^{17}$.

Asimismo, quise destacar que la manifestación discursiva de la experiencia de género- 
sexual es un aspecto que no puede soslayarse en la poesía de mujeres, en la medida en que entrega indicios acerca de las maneras diferenciales en que se articula la subjetividad femenina al interior de un entramado sociocultural androcéntrico. Y, al mismo tiempo, cómo dichas subjetividades se plasman en los textos mediante estilos y estrategias discursivas particulares que suponen tomas de posición políticas frente al contexto en que emerge la escritura, especialmente en los escenarios post-traumáticos que hemos venido revisando.

En cuanto a la productividad de la poesía en relación con estos temas, no puedo evitar pensar, como alguna vez lo sugirió el crítico brasileño Antonio Cândido (Antonio Cândido, 1995, p. 243), que ella, hoy más que nunca, es una práctica imprescindible. No sólo por el alto valor estético o histórico que posee, sino porque entrega elementos humanizadores y sanadores a los que todas las personas debieran tener acceso. Como afirma Cándido, si para las personas es imposible mantener el equilibrio psíquico sin soñar, es probable que no pueda haber equilibrio social sin literatura, en la medida en que ella confirma a los sujetos en su humanidad, incluso en gran medida porque actúa de forma inconsciente. Es por eso que, junto con otras formas de intervención consciente e intencional, cada sociedad ha creado sus propias manifestaciones ficcionales, poéticas y dramáticas, las que siempre tienen relación con sus impulsos, creencias, normas y deseos. De este modo, la literatura, como dice Cándido, no sólo afirma o niega, propone y denuncia, sino que provee a los seres humanos tanto de las herramientas como de la posibilidad de experimentar dialécticamente los problemas.

Como dejan en evidencia los textos de las poetas que he comentado en este trabajo, el juego libre con la imaginación y los recuerdos, así como la autorreflexión que está involucrada en el ejercicio poético, quizás sea un modo posible e idóneo para lidiar con experiencias y emociones que suelen sobrepasar nuestros recursos de comprensión racional. Por esta vía, entonces, también es posible que la poesía, y más ampliamente toda la literatura, pueda contribuir a estimular un proceso de resiliencia que nos devuelva, en tanto seres humanos, la capacidad de apertura hacia la complejidad del mundo y de los seres, haciéndonos más comprensivos y tolerantes frente a nosotros mismos, frente a nuestras propias trayectorias, y también frente a las de los otros y las otras.

\section{Bibliografía}

\section{Textos literarios}

Del Río, Alejandra (2009), material mente diario (1998-2008), Santiago de Chile, Cuarto Propio.

Iannamico, Roberta (2001), El collar de fideos, Bahía Blanca, Ediciones Vox.

Viola Fisher, Verónica (2005), Hacer sapito, Buenos Aires, Gog y Magog, (1 ${ }^{\text {ra }}$. edición, 1995).

\section{Bibliografía citada}

Amaro, Lorena «La enfermedad del regreso. Material mente diario de Alejandra del Río», http://lacallepassy061.blogspot. com/2009/09/la-enfermedad-del-regresomaterial.html. Consulta del 25 de abril de 2010.

Avellaneda, Andrés (2003), «Recordando con ira: estrategias ideológicas y ficcionales argentinas a fin de siglo», Revista Iberoamericana - Pittsburg, 60 (202), pp. 119-131.

Bello, Javier (2010), Poesía chilena 1990-2005. Antonia Torres, Andrés Anwandter, David Preiss, Alejandra del Río, Germán Carras$c o$, manuscrito.

- (2011), Memoria y negatividad en la poesía chilena de postdictadura (1990-2005). Cinco autores de la década del noventa: Antonia Torres, Andrés Andwandter, David Preiss, Alejandra del Río y Germán Carrasco, Tesis doctoral, Departamento de Filología Española, Clásica y Arabe, Universidad de las Palmas de Gran Canaria.

Butler, Judith (2006), Deshacer el género, Barcelona, Paidós.

Cândido, Antônio (1995), Vários escritos, São Paulo, Duas Cidades, $3^{a}$ edición.

Combariza, Helena (s/f), «La resilencia. El oculto potencial del ser humano». Disponible en internet en <http://aiur. us.es/ kobukan/la resilencia.htm>

Dalmaroni, Miguel (1993), Juan Gelman. Contra las fabulaciones del mundo, Buenos Aires, Almagesto.

Genovese, Alicia (2010), «Entre la ira el arte del olvido: testimonio e imagen poética», en VV.AA., Recordar para pensar. Memo-
Ecos antiguos en voces nuevas. Pos-memorias poéticas de mujeres en Chile y Argentina

ALICIA SALOMONE 
ria para la Democracia. La elaboración del pasado reciente en el Cono Sur de América Latina, Santiago de Chile, Ediciones Böll Cono Sur, pp. 69-76.

- (2003), «Marcas del graffiti en los suburbios: poesía argentina de la postdictadura», en Revista Iberoamericana - Pittsburgh; 60 (202), pp. 19-214.

Jelin, Elizabeth (2001), Los trabajos de la Memoria, Buenos Aires, Siglo XXI.

Monteleone, Jorge, Reseña bibliográfica «La niña bonita: entre el presente y la memoria», en http://proyectovox.org.ar/virtual 3.htm. Consulta del 27.3.2011.

- «Poetas en la mitad de la vida», en http:// www.lanacion.com.ar/1188416-poetasen-la-mitad-de-la-vida (consulta del 27.2.2011).

- «La niña bonita: entre el presente y la memoria», en http://proyectovox.org.ar/ virtual 3.htm. Consulta del 27.3.2011.

Violi, Patrizia (1991), El infinito singular, Madrid, Cátedra.
Waldman, Gilda (2007), «Post-memoria: una primera aproximación», en Maya Aguiluz Ibargüen y Gilda Waldman M. (coordinadoras), Memorias (in) cógnitas. Contiendas en la Historia, México, Universidad Nacional Autónoma de México.

Williams, Raymond (1980), Marxismo y literatura, Prólogo de J. M. Castellet, Barcelona, Península.

Páginas web

http://www.hijos-capital.org.ar/index. php?option $=$ com_content $\&$ view $=$ article \&id=20\&Itemid=399. Consulta del 23 de septiembre de 2011.

http://hijoschile.blogspot.com/. Consulta del 23 de septiembre de 2011.

http://hijosuruguay.blogspot.com/. Consulta del 23 de septiembre de 2011.

Fecha de recepción: 03/07/2011

Fecha de aprobación: 16/10/2011 